Research Article

\title{
Study on the Influence of Bending Angle of Multipoint Stretch-Bending of Profiles on Section Distortion of Parts
}

\author{
Jicai Liang $\mathbb{D},{ }^{1,2}$ Yanfei Liao $\mathbb{D}^{1,2}$ Yi Li ${ }^{1},^{1}$ and Ce Liang $\mathbb{D}^{1}$ \\ ${ }^{1}$ Key Laboratory of Automobile Materials, Ministry of Education, and College of Materials Science and Engineering, \\ Jilin University, Changchun 130025, China \\ ${ }^{2}$ Roll Forging Research Institute, Jilin University, Changchun, 130025 Jilin, China
}

Correspondence should be addressed to Yi Li; henrylee@jlu.edu.cn and Ce Liang; liangce@jlu.edu.cn

Received 12 August 2019; Accepted 20 January 2020; Published 19 February 2020

Academic Editor: Pablo Lopez-Crespo

Copyright (C) 2020 Jicai Liang et al. This is an open access article distributed under the Creative Commons Attribution License, which permits unrestricted use, distribution, and reproduction in any medium, provided the original work is properly cited.

\begin{abstract}
The ABAQUS finite element simulation software was used to simulate the flexible 3D multipoint stretch-bending (MPSB) forming process of aluminum profiles. The influence of bending angle on the section distortion was investigated. The results show that the type of rectangular section distortion during horizontal bending and vertical bending is different. The bulging rate and the depression rate increase with the increase in horizontal bending angles; when the vertical bending angle is less than $15^{\circ}$, the depression rate of the horizontally curved section is effectively reduced. When $\alpha$ is equal to $30^{\circ}, \beta$ is less than $15^{\circ}$ which can effectively reduce the depression rate caused by horizontal bending to the profile. When $\alpha$ is less than $30^{\circ}$, the depression rate which is caused by horizontal bending can be reduced through the vertical bending angle, with $5^{\circ}$ than $15^{\circ}$; the vertical bending process changes the distortion pattern of the profile; the depression rate and the bulging rate increase with the increase of the vertical bending angle. Through the support vector regression and selecting the parameter group $c=1.5, g=0.05$, the distortion rate of different angles in the common range is further expanded, and the quality control curve is drawn by combining the test results and prediction results which determine the depression rate as $2 \%, 2.5 \%$, and $3 \%$ processing boundary. Using this curve to predict the distortion rate of the profile is instructive in the actual processing.
\end{abstract}

\section{Introduction}

Due to the rapid development of the automobile and highspeed rail industry in recent years, people pay more and more attention to the lightweight design of the structure. This is because reducing the weight of cars and high-speed trains can not only reduce energy consumption and alleviate the growing energy crisis but also reduce waste emissions [1-3]. Aluminum has a wide range of properties such as low density, high strength, and easy recycling, so it is widely used in aerospace, rail vehicle, and automotive manufacturing.

The rapid development of the manufacturing industry has made the demand for parts more diversified. The traditional processing methods are limited to two-dimensional bending and forming, or the three-dimensional deformation is realized by manual torsion after two-dimensional bending of the profile. This method is time-consuming and laborious, and the scrap rate is high. Clausen et al. used the finite element method to simulate the bending and forming process of the car bumper and conducted in-depth research on the section distortion and springback phenomenon [4]. Vaze and Corona used experimental methods to study the wrinkle line of the rectangular profile bending process [5]; Corona proposed an effective method for predicting crosssection distortion of thin-walled profiles [6]. In order to reduce the production cost and shorten the production cycle time, combined with the technical characteristics of threedimensional flexible bending, a team under Liang Jicai professor from Jilin University developed a new three-dimensional flexible multipoint stretch-bending technology has been developed, which can realize the complex forming of three-dimensional parts. The mold profile of this processing method is reconfigurable [7-9]. Teng et al. explored 
the prediction of the amount of springback in the threedimensional stretch-bending process of the profile [10], and Liang et al. explored the forming of the profile in threedimensional stretch-bending [11]. Yu et al. explored the extent to which processing parameters affect the distortion of profiles [12].

In the process of three-dimensional stretch-bending, the profile is a light high-strength aluminum alloy with large deformation resistance and good plasticity. Distortion is a significant defect in the forming process. Because the technology is at the forefront, engineers lack experience in multipoint stretch-bending [13]. They are unable to predict whether a profile will be distorted. Therefore, a large amount of waste parts may be processed, resulting in an increase in cost [14-16]. So, exploring the variation law of cross-section distortion of aluminum profiles during three-dimensional stretch-bending has certain guiding significance for actual production [17-19]. This paper investigates the influence of the bending angle of the profile on the cross-section distortion and the variation law.

\section{Concept of Flexible 3D Stretch-Bending and FE Model}

2.1. Description of the 3D Stretch-Bending Process. The basic principle of multipoint flexible forming of profiles is to bend the profiles in horizontal and vertical directions, respectively. Since the contact between the profile and multipoint dies is not continuous, the multipoint dies can be moved and rotated in both horizontal and vertical planes. Therefore, there is greater flexibility and diversity for forming a target envelope surface in space. The steps of three-dimensional multipoint stretch-bending processing are shown in Figure 1. $M_{h}$ and $M_{v}$ represent the bending moments in the horizontal and vertical planes, respectively. $T_{1}$ and $T_{2}$ represent the axial tensile forces in the horizontal and vertical planes, respectively.

(1) Profile in the $y-z$ plane: adjust the position parameters of each flexible unit of the multipoint dies to form the desired horizontal envelope surface

(2) Prestretching: under the tensile action of the axial force of the clamp, the profile is stretched to the plastic state, and the purpose of the pre-stretching is to effectively reduce the springback defect of the three-dimensional of profiles, and the prestretching amount is generally $0.5 \%-1 \%$

(3) Horizontal bending deformation in the $y-z$ plane: the profile is pulled by the clamp in the horizontal $y-z$ plane, so that the profile gradually abuts the horizontal envelope surface formed by the multi-point dies (Figure 1(a))

(4) Vertical bending deformation in the $x$ - $z$ plane: after the horizontal bending in the $y-z$ plane is completed, the profile is pulled along the $x$-axis under the traction of the clamp (Figure 1(b))

(5) Post-Stretching: after the horizontal and vertical bending processes are completed, the deformed profile is further stretched under the traction of the clamp, so that the spring back defect of the formed part can be more effectively reduced, and the amount of poststretching is generally $0.5 \%-0.8 \%$

2.2. Material Model. Aluminum alloy materials are widely used in the railway industry and automotive fields due to their good mechanical properties and low density. In the finite element model, the material used was a $6005 \mathrm{~A}$ aluminum alloy. In order to accurately describe the change of cross-sectional area during large deformation, it is necessary to use true strain $\left(\varepsilon_{\text {true }}\right)$ and true stress $\left(\sigma_{\text {true }}\right)$. Their conversion formula between nominal strain and nominal stress is as follows:

$$
\begin{gathered}
\varepsilon_{\text {true }}=\int_{l_{0}}^{l} \frac{\mathrm{d} l}{l}=\ln \left(\frac{l}{l_{0}}\right)=\ln \left(1+\varepsilon_{\text {nom }}\right), \\
\sigma_{\text {true }}=\frac{F}{A}=\frac{F}{A_{0}\left(l_{0} / l\right)}=\sigma_{\text {nom }}\left(1+\varepsilon_{\text {nom }}\right) .
\end{gathered}
$$

The rectangular profile with a length of $3600 \mathrm{~mm}$ has a cross-section dimension of $40 \times 30 \mathrm{~mm}$ and a wall thickness of $2 \mathrm{~mm}$. The length of the curved portion is $2840 \mathrm{~mm}$, and isotropic is assumed for the profile material. The stress-strain relationship of the material constitutive is expressed as

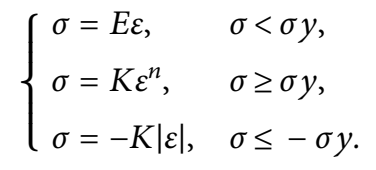

The mechanical properties of the material follow the Mises yield criterion and the Prandtl-Ruess flow rule. Yield strength $\left(\sigma_{y}\right)$ is $260 \mathrm{Mpa}$, elastic modulus $(E)$ is $70 \mathrm{Gpa}$, Poisson's ratio $(\nu)$ is 0.3 , density $(\rho)$ is $2.71 \mathrm{~g} \mathrm{~cm}^{-3}$, and friction coefficient is 0.15 . Intensity factor $(K)$ is $398.87 \mathrm{MPa}$, and strain enhancement index $(n)$ is 0.154 .

2.3. Establishment of the Finite Element Model. The numerical simulation of 3D stretch-bending is performed using ABAQUS/Explicit. Because the geometry of the profile and the operation of the forming process are symmetrical, the $1 / 2$ model is used for analysis. The total model consists of profiles, clamps, multipoint dies, and limit screws. The clamps are used to apply tension and bending moments. Limit screws control the displacement of the profile by limiting the displacement of the clamp $[15,16]$. The threedimensional stretch-bending of aluminum profiles during the simulation process is a three-dimensional simulation problem, which will cause grid distortion. According to the principle of solid element selection, the solid element C3D8R can be selected for the aluminum profile. C3D8R is a hexahedral linearly reduced integral solid element with 8 nodes for large strain and deformation. Multipoint dies, limit screws, and clamps are modeled using the rigid unit R3D4, since the rigid unit is mainly used to simulate very strong components that can be either fixed or moving. Since the rigid body unit does not calculate the unit hierarchy in 


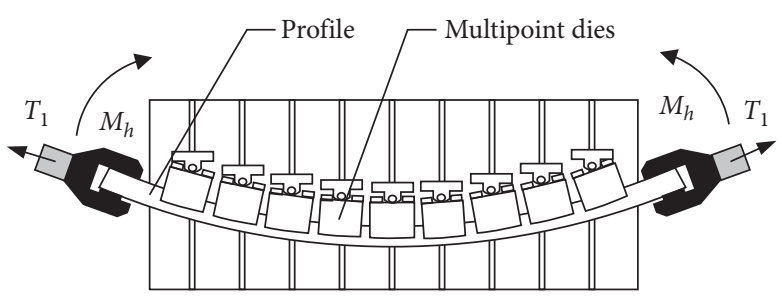

(a)

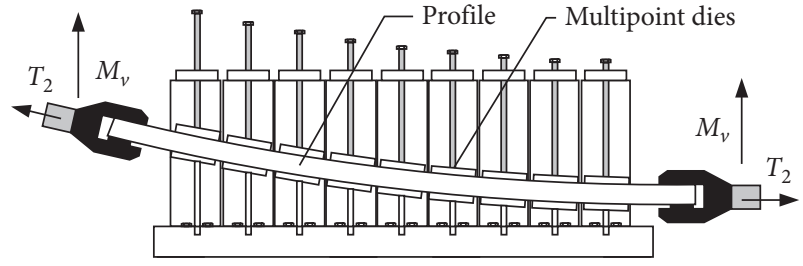

(b)

FIGURE 1: Schematic diagram of three-dimensional multipoint stretch-bending. (a) Bending forming in horizontal direction. (b) Bending forming in vertical direction.

the simulation calculation, the calculation time can be significantly shortened. The classical Coulomb model is chosen to represent the interface friction condition $\sigma_{f}=\mu\left|\sigma_{n}\right|$, in which $\sigma_{f}$ is the friction stress and $\mu$ is the friction coefficient and the $\sigma_{n}$ is the positive pressure. The assembled 3D flexible stretch-bending model is shown in Figures 2(a) and 2(b) is the result after the profile completed three-dimensional stretch-bending. A schematic diagram of horizontal and vertical bending is shown in Figure 3. Figure 3(a) shows a horizontal bending process and $\alpha$ represents an angle of horizontal bending. Figure 3(b) shows a vertical bending process, and $\beta$ represents a vertical bending angle. The trajectory of the clamp is as follows:

Horizontal bending:

$$
\begin{aligned}
& \Delta z=\left(L+\delta_{\text {pre }}\right)-\left\{R \sin \alpha+\left[\left(L+\delta_{\text {pre }}\right)-R \alpha\right] \cos \alpha\right\}, \\
& \Delta y=R(1-\cos \alpha)+\left[\left(L+\delta_{\text {pre }}\right)-R \alpha\right] \sin \alpha .
\end{aligned}
$$

Vertical bending:

$$
\begin{aligned}
\Delta x & =(1-\cos \beta) r+\left[L_{2}-L_{1}\right] \frac{\sin \beta}{\cos \beta}, \\
r & =\frac{L_{1}}{\sin \beta}, \\
L_{1} & =R \sin \alpha, \\
L_{2} & =R \sin \alpha+\left[\left(L+\delta_{\text {pre }}\right)-R \alpha\right] \cos \alpha .
\end{aligned}
$$

Poststretching:

$$
\begin{aligned}
& x=\delta_{\mathrm{po}} \sin \beta, \\
& y=\delta_{\mathrm{po}} \cos \beta \sin \alpha, \\
& z=\delta_{\mathrm{po}} \cos \beta \cos \alpha .
\end{aligned}
$$

Here, $L$ is the length of the profile, $\delta_{\text {pre }}$ is the value of prestretching, $R$ is the horizontal bending radius, $R 1$ is the vertical bending radius, $\alpha$ is the horizontal bending angle, $r$ is the vertical bending radius, $\beta$ is the vertical bending angle, $L 2$ represents the length of the profile projected in the vertical plane, $L 1$ is the projection length of the contact part between the profile and the multipoint dies in the vertical plane, and $\delta_{\text {po }}$ is the value of poststretching.

\section{Experiments and Discussion}

3.1. Study on the Section Distortion of Rectangular Profiles during Horizontal and Vertical Bending. The section is distorted during the bending of rectangular section profile, and the distortion of rectangular section is usually the depression of outer web and bulging of the side wall. The distortion of rectangular section profile can be represented by the depression rate and bulging rate of the rectangular section. The schematic diagram is shown in Figure 4. In Figure $4, B_{0}$ represents the length of the rectangular section before deformation, $B$ represents the length of the rectangular section after deformation, $H_{0}$ represents the height of the rectangular section before deformation, and $H$ represents the height of the rectangular section after deformation. $\left(B-B_{0}\right) / B$ indicates the bulging rate, and $\left(H-H_{0}\right) / H$ indicates the depression rate $[17,18]$. The variation of depression rate and bulging rate with the bending angle and the type of bulging rate has been studied [19]. When the horizontal bending is completed, the distortion of cross section is shown in Figure 4(a). When the vertical bending is completed, the cross section of the rectangular profile is distorted as shown in Figure 4(b). And Figure 5(a) shows the numerical simulation results which show the aluminum profile that completed three groups of numerical simulations which are $\alpha=20^{\circ} \beta=0^{\circ}, \alpha=25^{\circ} \beta=0^{\circ}$, and $\alpha=30^{\circ} \beta=0^{\circ}$. Figure 5(b) shows the results of numerical simulation which show the aluminum profile that completed three groups of numerical simulations which are $\alpha=30^{\circ} \beta=20^{\circ}, \alpha=20^{\circ} \beta=30^{\circ}$, and $\alpha=25^{\circ} \beta=25^{\circ}$. The variation of the distortion rate of the rectangular profile completed the horizontal bending of $10^{\circ}$, $15^{\circ}, 20^{\circ}, 25^{\circ}$, and $30^{\circ}$ as shown in Figure 6 . With the increase in horizontal bending angle, the depression rate and bulging rate of the rectangular section gradually increase.

3.2. Distortion Rate Change of Rectangular Section after 3D Stretch-Bending. Numerical simulation of $\alpha$ and $\beta$ was carried out at different angles. The depression rate of rectangular profile after horizontal and vertical bending is shown in Table 1, and the bulging rate is shown in Table 2. The depression rate after the rectangular profile completed poststretching is shown in Table 3, and the bulging rate is shown in Table 4 . The results show that when the horizontal bending is completed, the depression rate and bulging rate of section have increased with the bending angle; when the vertical bending angle is less than $15^{\circ}$, the depression rate has 


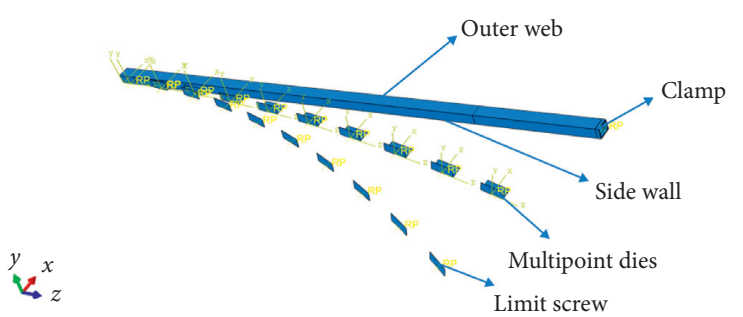

(a)

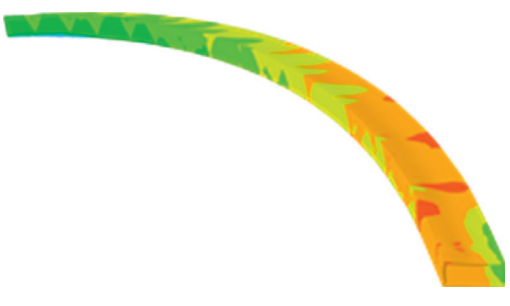

(b)

Figure 2: (a) Assembled three-dimensional flexible bending model and (b) modeling result.

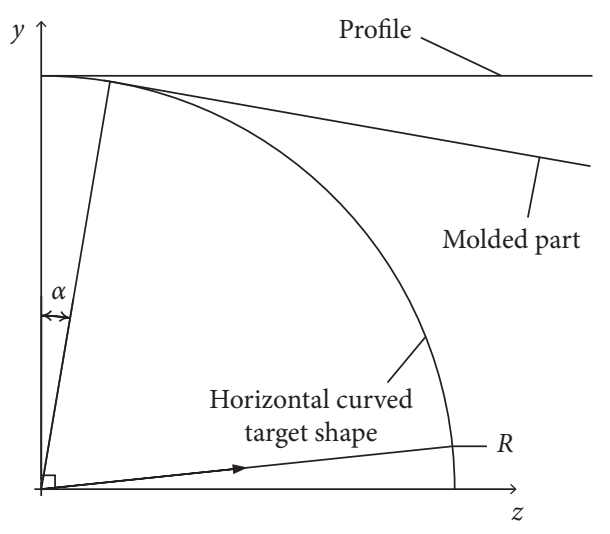

(a)

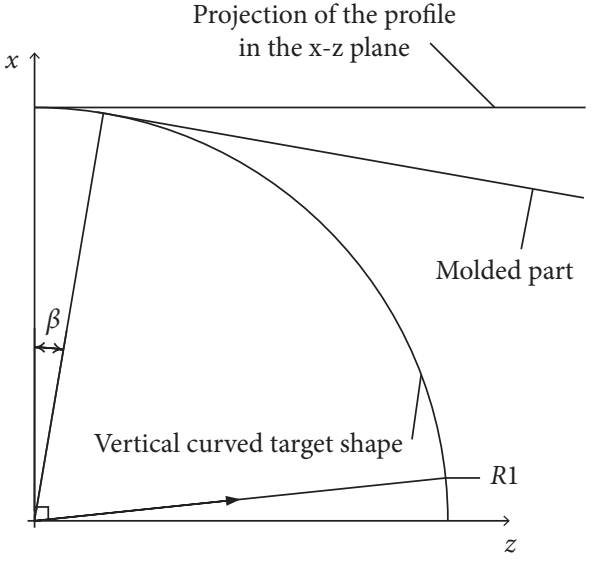

(b)

FIgURE 3: (a) Horizontal bending and (b) vertical bending processes.

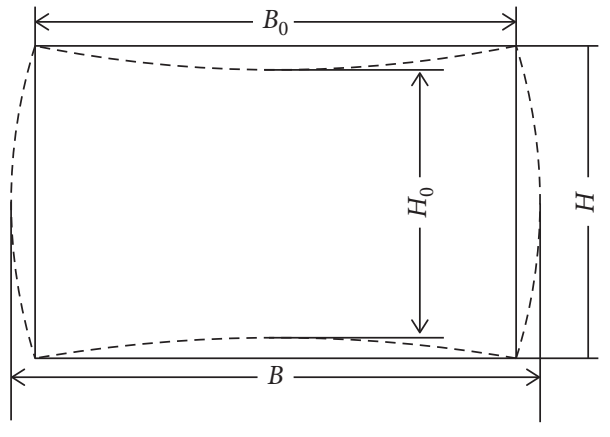

(a)

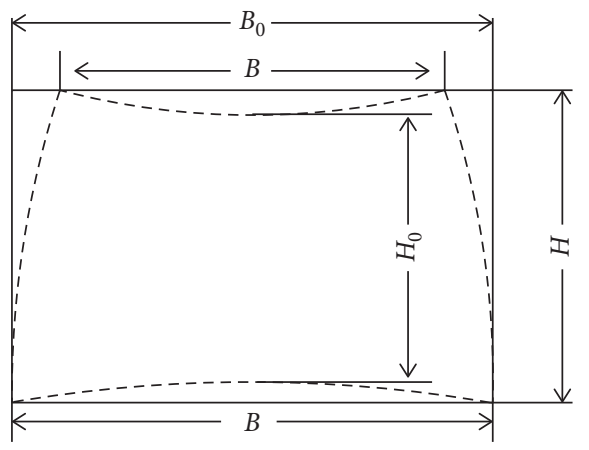

(b)

Figure 4: Distortion of rectangular section profile.

a certain degree recovery. The vertical bending causes the form of distortion to change; the depression rate and bulging rate both increase with the increase in vertical bending angle. The depression rate and bulging rate increase slightly during the poststretching stage.

The processing device of 3D multipoint stretch-bending is shown in Figure 7. In this paper, the profile used in the front frame of high-speed rail train is chosen as the experimental part, and the experimental study is carried out. The depression rate of the section when the vertical bending is completed is shown in Table 5, and the bulging rate of the section when the vertical bending is completed is shown in Table 6 . The depression rate of the rectangular cross section at the time of completion of poststretching is as shown in Table 7, and the bulging rate is as shown in Table 8.

The comparison between the experimental data and the numerical simulation data is shown in Figure 8. The deviation between the simulated data and the experimental data is not large. Also, the numerical simulation data is close to the actual situation of the actual processing and has certain credibility. 


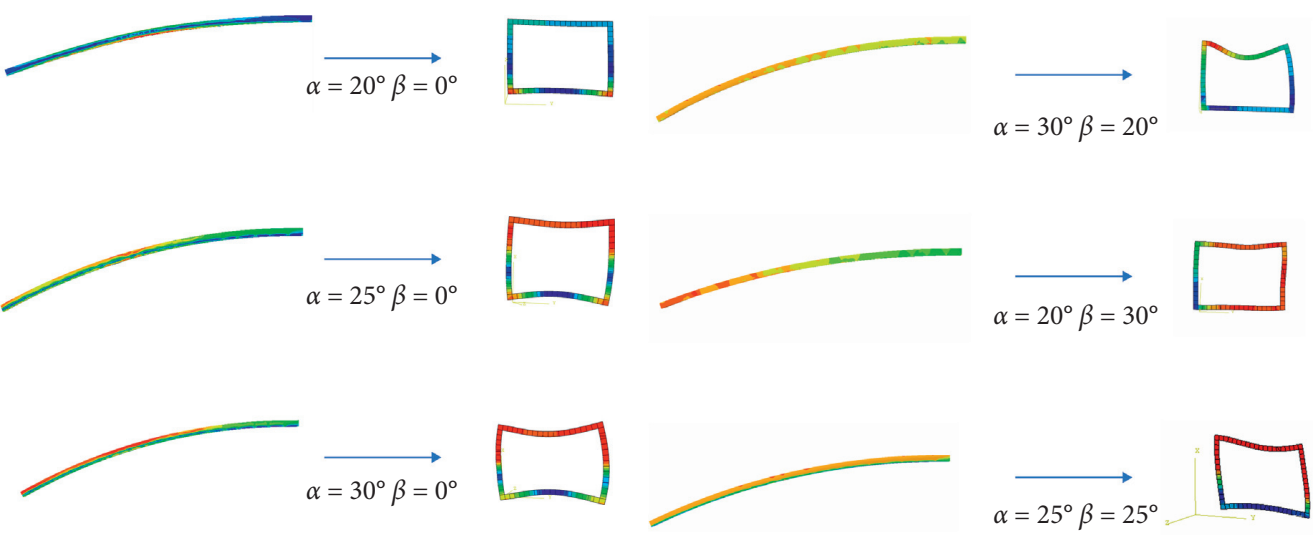

(a)

(b)

FIGURE 5: Numerical simulation results.

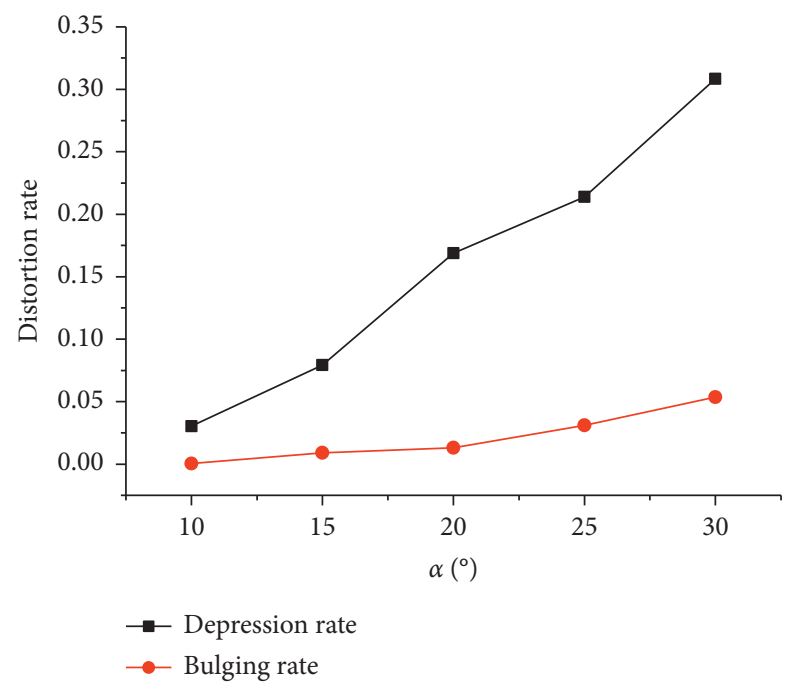

FIGURE 6: Depression rate and bulging rate results.

TABLE 1: Depression rate after simulated vertical bending.

\begin{tabular}{|c|c|c|c|c|c|}
\hline \multirow{2}{*}{$\beta$} & \multicolumn{5}{|c|}{$\alpha$} \\
\hline & $10^{\circ}$ & $15^{\circ}$ & $20^{\circ}$ & $25^{\circ}$ & $30^{\circ}$ \\
\hline $0^{\circ}$ & 0.0304626 & 0.0791167 & 0.1687423 & 0.2140013 & 0.3083467 \\
\hline $10^{\circ}$ & 0.0178986 & 0.0676890 & 0.0746023 & 0.1754750 & 0.2724500 \\
\hline $15^{\circ}$ & 0.0271380 & 0.0754400 & 0.0782530 & 0.1890000 & 0.2768500 \\
\hline $20^{\circ}$ & 0.0275300 & 0.0774240 & 0.0804483 & 0.1946777 & 0.3097000 \\
\hline $25^{\circ}$ & 0.0295446 & 0.0929856 & 0.0976320 & 0.2379536 & 0.3617567 \\
\hline $30^{\circ}$ & 0.0420127 & 0.1188397 & 0.1386000 & 0.3011980 & 0.4200900 \\
\hline
\end{tabular}

TABLE 2: Bulging rate after simulated vertical bending.

\begin{tabular}{lccccc}
\hline$\beta$ & & & $\alpha$ & & \\
& $10^{\circ}$ & $15^{\circ}$ & $20^{\circ}$ & $25^{\circ}$ & 0.0311640 \\
\hline $0^{\circ}$ & 0.0004162 & 0.0089895 & 0.0130539 & 0.0003263 & 0.0124940 \\
$10^{\circ}$ & -0.0174793 & -0.0154551 & -0.0123915 & -0.0214200 & -0.0066452 \\
$15^{\circ}$ & -0.0383300 & -0.0359875 & -0.0298900 & -0.0620000 & -0.0467800 \\
$20^{\circ}$ & -0.0808560 & -0.07863000 & -0.0726098 & -0.0725793 & -0.0478300 \\
$25^{\circ}$ & -0.0932673 & -0.0915635 & -0.08539758 & -0.0932693 & -0.0712990 \\
$30^{\circ}$ & -0.1324000 & -0.1070648 & -0.0965000 & & \\
\hline
\end{tabular}


TABLE 3: Depression rate after simulated poststretching.

\begin{tabular}{lccccc}
\hline$\beta$ & & & $\alpha$ & & \\
& $10^{\circ}$ & $15^{\circ}$ & $20^{\circ}$ & 0.2140016 & $30^{\circ}$ \\
\hline $0^{\circ}$ & 0.0304628 & 0.0791167 & 0.1687424 & 0.1758433 & 0.3083475 \\
$10^{\circ}$ & 0.0179250 & 0.0685251 & 0.0747300 & 0.1985670 & 0.2831747 \\
$15^{\circ}$ & 0.0271560 & 0.0764500 & 0.0805240 & 0.2088277 & 0.2931110 \\
$20^{\circ}$ & 0.0286000 & 0.0785293 & 0.0835790 & 0.2660827 & 0.3206023 \\
$25^{\circ}$ & 0.0305420 & 0.0953324 & 0.0988700 & 0.3273853 & 0.3942551 \\
$30^{\circ}$ & 0.0443280 & 0.1279246 & 0.1435220 & & 0.4357420 \\
\hline
\end{tabular}

TABLE 4: Bulging rate after simulated poststretching.

\begin{tabular}{|c|c|c|c|c|c|}
\hline \multirow{2}{*}{$\beta$} & \multicolumn{5}{|c|}{$\alpha$} \\
\hline & $10^{\circ}$ & $15^{\circ}$ & $20^{\circ}$ & $25^{\circ}$ & $30^{\circ}$ \\
\hline $0^{\circ}$ & 0.0004162 & 0.0089895 & 0.0130539 & 0.0311641 & 0.0489172 \\
\hline $10^{\circ}$ & -0.0174900 & -0.0169855 & -0.0152959 & 0.0016500 & 0.0128708 \\
\hline $15^{\circ}$ & -0.0387580 & -0.0364421 & -0.0345280 & -0.0285162 & -0.0139668 \\
\hline $20^{\circ}$ & -0.0834250 & -0.0794250 & -0.0755765 & -0.0656095 & -0.0476398 \\
\hline $25^{\circ}$ & -0.0957750 & -0.0932620 & -0.0899650 & -0.0768650 & -0.0482000 \\
\hline $30^{\circ}$ & -0.1356230 & -0.1241900 & -0.1174840 & -0.0943848 & -0.0742510 \\
\hline
\end{tabular}



Figure 7: Device of 3D multipoint stretch-bending.

TABLe 5: Depression rate after experimental vertical bending.

\begin{tabular}{lccccc}
\hline$\beta$ & \multicolumn{5}{c}{$\alpha$} \\
& $10^{\circ}$ & $15^{\circ}$ & $20^{\circ}$ & $25^{\circ}$ & $30^{\circ}$ \\
\hline $0^{\circ}$ & 0.02546 & 0.07526 & 0.1858867 & 0.22756441 & 0.2988579 \\
$10^{\circ}$ & 0.015894 & 0.07085425 & 0.0839968 & 0.1782481 & 0.2628524 \\
$15^{\circ}$ & 0.02815 & 0.0754662 & 0.079652 & 0.1855874 & 0.282257 \\
$20^{\circ}$ & 0.02953 & 0.08524 & 0.088353 & 0.198468 & 0.34397 \\
$25^{\circ}$ & 0.029 & 0.092932 & 0.09542331 & 0.2574825 & 0.3617567 \\
$30^{\circ}$ & 0.04201523 & 0.118452 & 0.12685113 & 0.2859684 & 0.3859724 \\
\hline
\end{tabular}

3.3. Machine Learning Determines the Range of Horizontal and Vertical Bending Angles that Match Different Forming Accuracies. The machine learning method is a method of using probabilistic statistical means to learn the probability distribution or classification of the data from known smallscale samples and then predict the unknown sample points. SVM (Support Vector Machine) is a machine learning method based on the minimization of statistical theory and structural risk, which can effectively solve some defects of neural networks. SVM can solve the regression problem, classification problem, and clustering problem. It is a regression problem to predict the boundary of different machining precisions of aluminum profiles in the threedimensional bending process. The support vector machine used for regression prediction is called SVR (Support Vector Regression). SVR can obtain good statistical laws and generalization ability when the sample data are small. It has been widely used in the field of regression prediction.

For the linear indivisible problem of the distortion rate data of the rectangular profile, that is, the positive and negative samples cannot be separated by a straight line, and the SVR is solved by using a kernel function. The common kernel functions include a linear kernel and an RBF core, as shown in Table 9.

The results of finite element numerical simulation show that the variation of the depression rate is more obvious and the range of bulging rate is not obvious. Therefore, the depression rate is used as the main index of machine learning. Different kernel functions contain different parameters. In this paper, the RBF kernel function, that is, Gaussian kernel, is selected, and its parameter " $g$ " ( $g \in[0.005$, $0.2])$ and penalty parameter " $c$ " $(c \in[0.1,10])$ are grid search analysis. The six comparison graphs show the difference between the prediction results of the different parameters on the training set and the training set as shown in Table 10, wherein the green curve is the result of the profile depression rate normalized to $[-1,1]$ which is the finite element analysis model above that finished different angles horizontal bending and vertical bending, and the red curve is the prediction of the distortion rate of the SVR according to different bending angles, and the horizontal and vertical angles correspond to the green curve one by one. Although most of them can basically restore the general trend, the parameter group $c=1.5$ and $g=0.05$ can better show the details of the change, and the correlation coefficient is the highest. Therefore, SVR, with the parameter group Gaussian kernel, is selected to expand the MPSB finite element numerical simulation data. 
TABLE 6: Bulging rate after experimental vertical bending.

\begin{tabular}{lccccc}
\hline$\beta$ & & & $\alpha$ & $20^{\circ}$ & $30^{\circ}$ \\
\hline $0^{\circ}$ & $10^{\circ}$ & $15^{\circ}$ & $20^{\circ}$ & 0.042886 & 0.0498425 \\
$10^{\circ}$ & 0.0004168 & 0.00852874 & 0.0152615 & 0.0003862 & 0.015241 \\
$15^{\circ}$ & -0.0174857 & -0.0167582 & -0.0105269 & -0.025246 & -0.006246 \\
$20^{\circ}$ & -0.0358625 & -0.0359875 & -0.0292957 & -0.057418 & -0.045286 \\
$25^{\circ}$ & -0.0758655 & -0.0725214 & -0.0697842 & -0.085964 & -0.047428 \\
$30^{\circ}$ & -0.0972544 & -0.0918545 & -0.08534288 & -0.0938641 & -0.0765822 \\
\hline
\end{tabular}

TABle 7: Depression rate after experimental poststretching.

\begin{tabular}{|c|c|c|c|c|c|}
\hline \multirow{2}{*}{$\beta$} & \multicolumn{5}{|c|}{$\alpha$} \\
\hline & $10^{\circ}$ & $15^{\circ}$ & $20^{\circ}$ & $25^{\circ}$ & $30^{\circ}$ \\
\hline $0^{\circ}$ & 0.0304625 & 0.0791165 & 0.1647427 & 0.2340015 & 0.3183475 \\
\hline $10^{\circ}$ & 0.0174215 & 0.0682485 & 0.0745264 & 0.1753252 & 0.2588622 \\
\hline $15^{\circ}$ & 0.0252682 & 0.0806625 & 0.0826857 & 0.1982266 & 0.2985663 \\
\hline $20^{\circ}$ & 0.0282285 & 0.0825774 & 0.0835228 & 0.2056641 & 0.3222485 \\
\hline $25^{\circ}$ & 0.0327458 & 0.0953642 & 0.0995667 & 0.2588216 & 0.3928993 \\
\hline $30^{\circ}$ & 0.0425617 & 0.1226518 & 0.1256553 & 0.3272258 & 0.4357635 \\
\hline
\end{tabular}

TABLE 8: Bulging rate after the experimental poststretching.

\begin{tabular}{|c|c|c|c|c|c|}
\hline \multirow{2}{*}{$\beta$} & \multicolumn{5}{|c|}{$\alpha$} \\
\hline & $10^{\circ}$ & $15^{\circ}$ & $20^{\circ}$ & $25^{\circ}$ & $30^{\circ}$ \\
\hline $0^{\circ}$ & 0.0004161 & 0.0089856 & 0.0150524 & 0.0311635 & 0.0529178 \\
\hline $10^{\circ}$ & -0.0178574 & -0.0154926 & -0.015264 & 0.0015288 & 0.0118561 \\
\hline $15^{\circ}$ & -0.0362588 & -0.0427757 & -0.032685 & -0.0282655 & -0.015188 \\
\hline $20^{\circ}$ & -0.0852614 & -0.0882644 & -0.078667 & -0.0628854 & -0.058699 \\
\hline $25^{\circ}$ & -0.0928592 & -0.0985268 & -0.084286 & -0.0741552 & -0.045168 \\
\hline $30^{\circ}$ & -0.1342695 & -0.1285664 & -0.117266 & -0.0985697 & -0.077847 \\
\hline
\end{tabular}

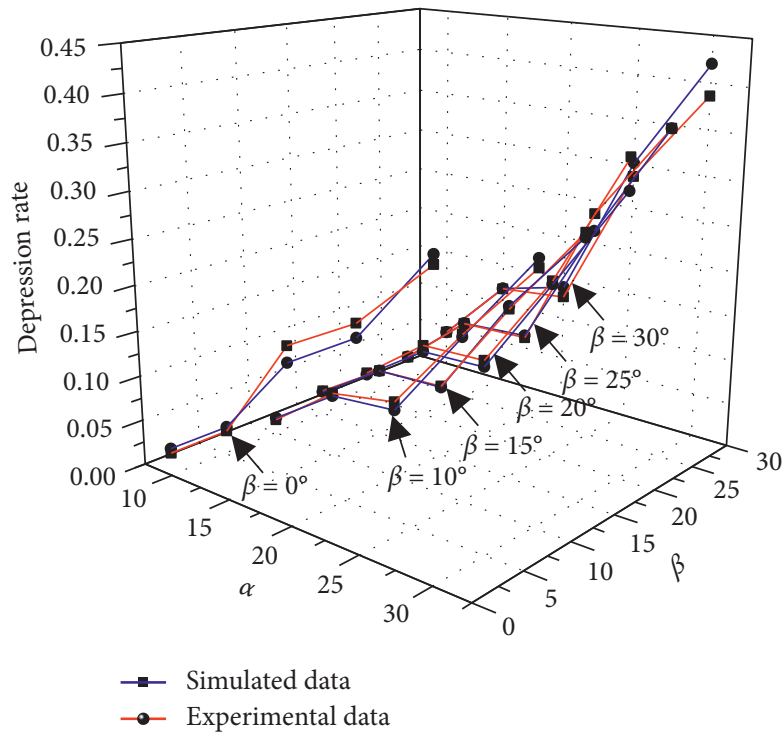

(a)

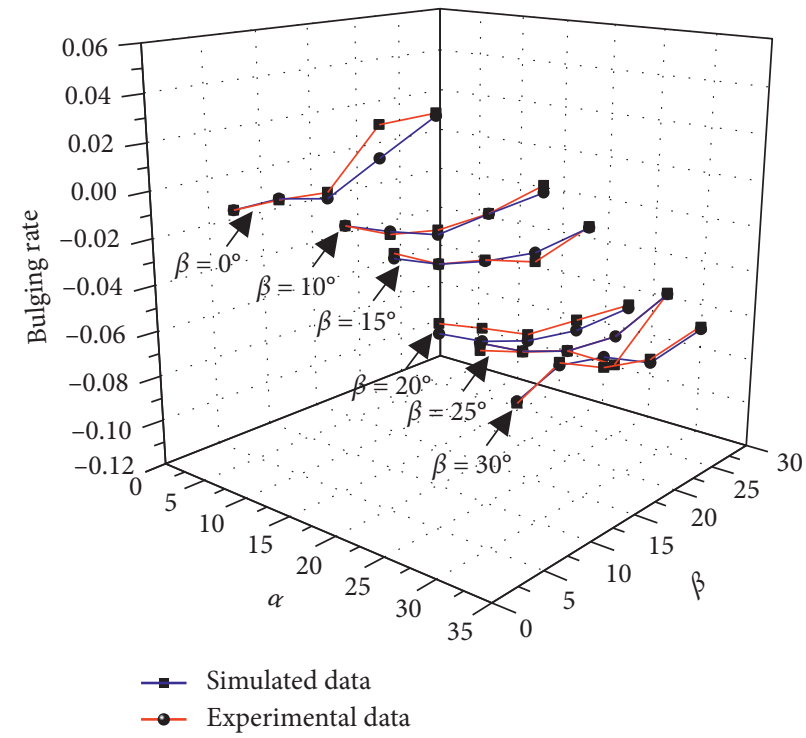

(b)

FIgure 8: Continued. 




(c)

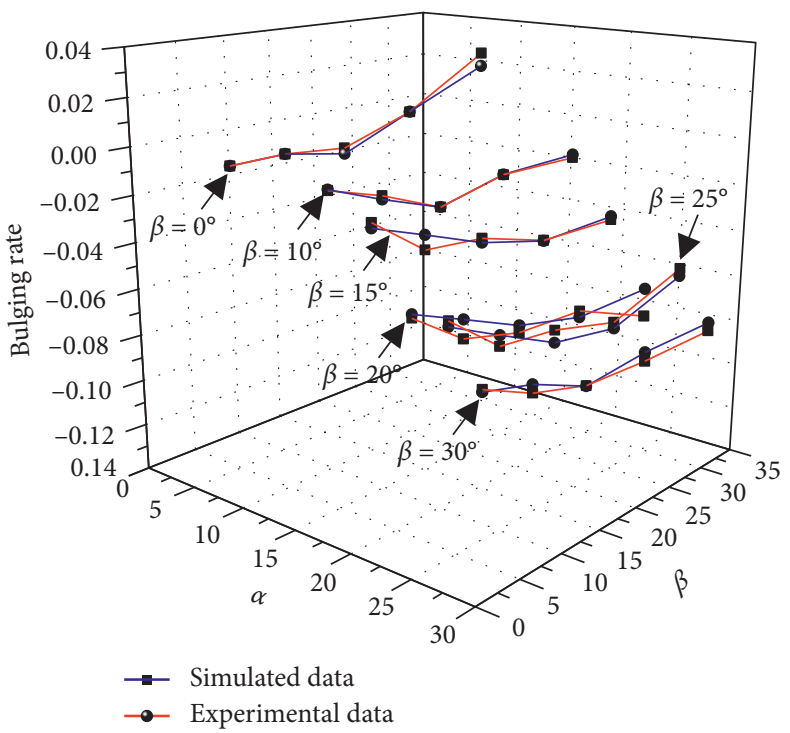

(d)

Figure 8: Comparison between the experimental data and the numerical simulation data.

TABLE 9: Common kernel functions.

\begin{tabular}{lcc}
\hline Kernel function name & \multicolumn{1}{c}{ Expression } \\
\hline Linear core & $k\left(x_{i}, x_{j}\right)=x_{i} T x_{j}$ & Parameter \\
Polynomial kernel & $k\left(x_{i}, x_{j}\right)=\left(x_{i} T x_{j}\right) d$ & $d \geq 1$ is the number of polynomials \\
Gaussian core & $k\left(x_{i}, x_{j}\right)=\exp \left(-\left(\|x i-x j\|^{2} / \sigma^{2}\right)\right)$ & $\sigma>0$ bit Gaussian kernel bandwidth \\
Laplace core & $k\left(x_{i}, x_{j}\right)=\exp (-(\|x i-x j\| / \sigma))$ & $\sigma>0$ \\
Sigmoid core & $k\left(x_{i}, x_{j}\right)=\tanh \left(\beta x_{i} T x_{j}+\theta\right)$ & Tanh is a hyperbolic tangent function, $\beta>0, \theta<0$ \\
\hline
\end{tabular}

TABLE 10: Effect of different parameters on regression results.

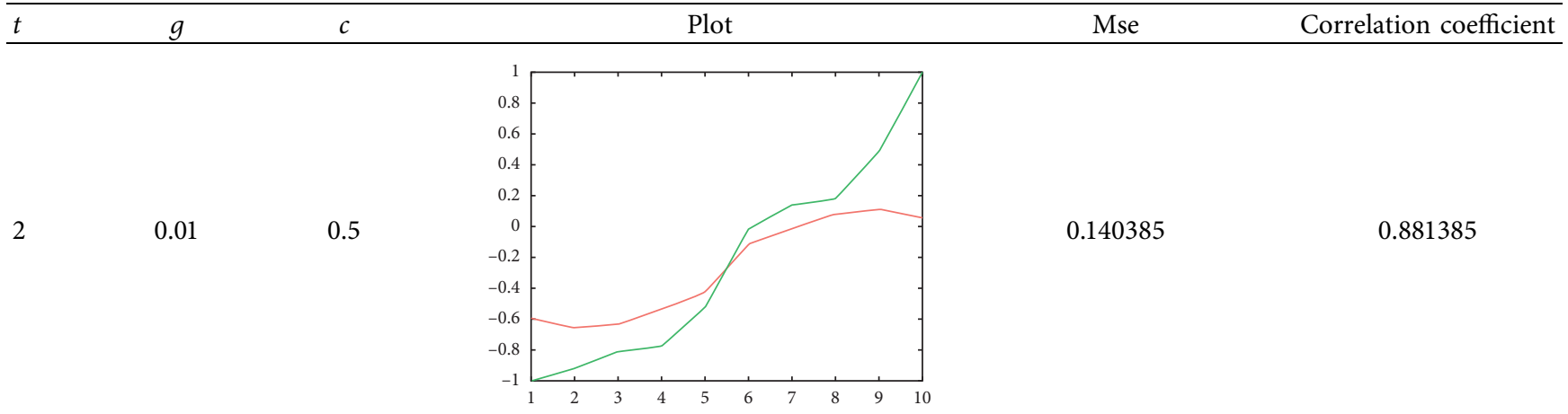
0.01 1



0.0556929 
Table 10: Continued.

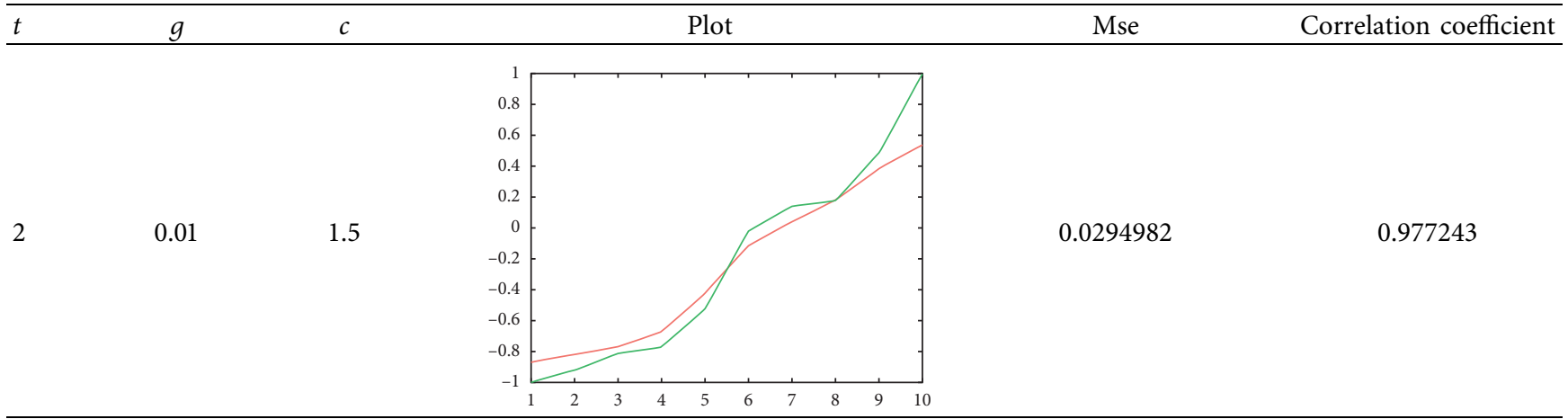

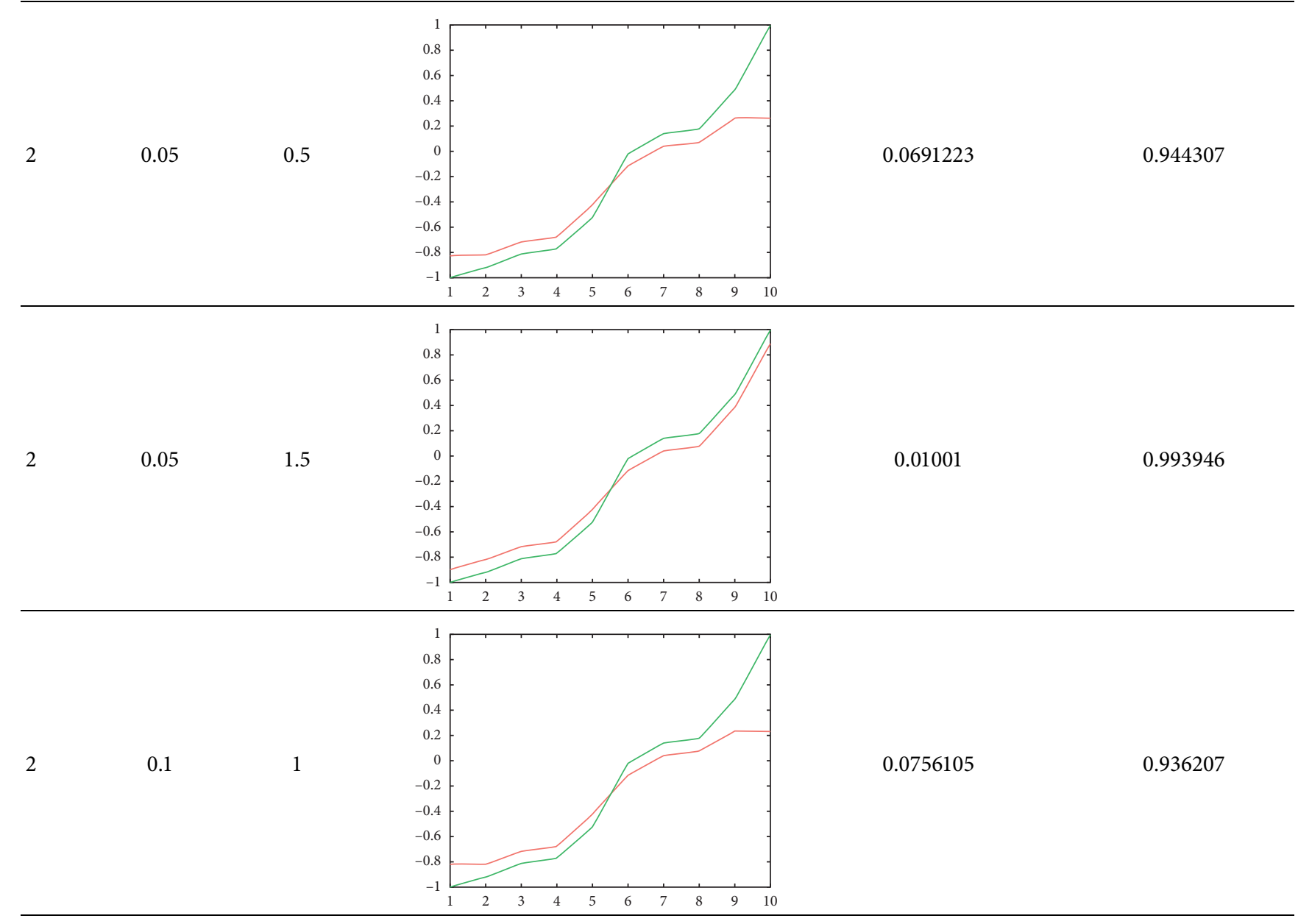

This paper uses the LIBSVM software package to implement SVM regression prediction. It not only provides executable files under the compiled Windows series system but also provides source code for easy modification and improvement.

In the actual processing process, the parts will choose different processing precision according to the use. Drawing the quality control curve will help the workers to judge the quality of the processed profiles. Using the finite element simulation results to plot the allowable range of horizontal bending and vertical bending angles under different forming precisions will be of great significance for guiding production. The reasonable data extended by machine learning determine the boundary of the depression rate less than $2 \%$, $2.5 \%$, and $3 \%$, as shown in Figure 9, and the workers can process according to the range in the figure during actual production.

\section{Conclusions}

(1) In this paper, the distortion rate of rectangular section profiles is studied in the flexible three-dimensional multipoint bending process. The numerical simulation is used to obtain the variation law of the distortion rate of the rectangular profile during 


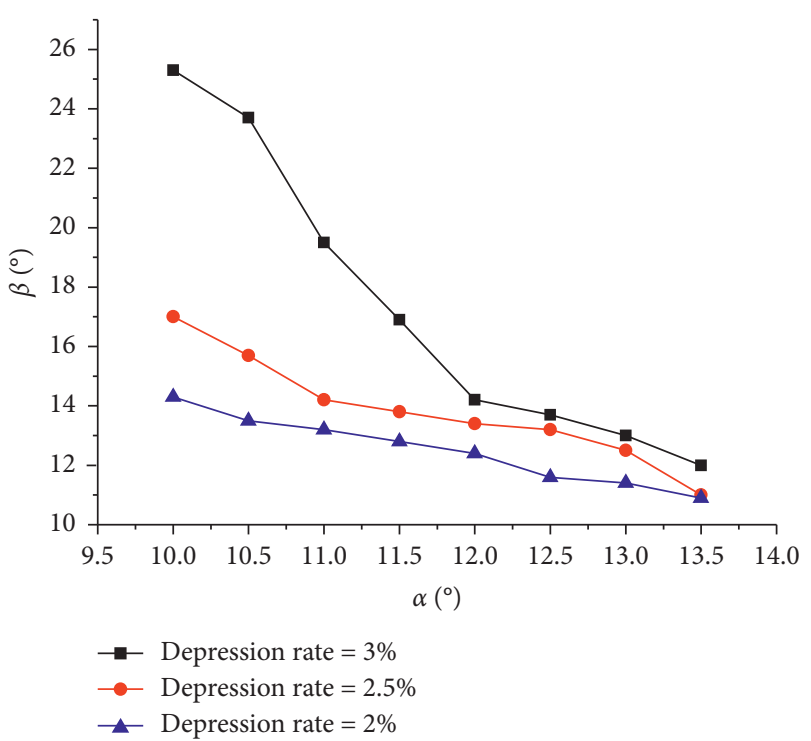

FIGURE 9: Boundary of depression rate.

the horizontal and vertical bending processes and the variation of the distortion: the depression rate and the bulging rate of the rectangular section increase with the increase of the bending angle during the horizontal bending process; when the vertical bending angle is small, the depression rate can be reduced to a certain extent, and the depression rate and the bulging rate of the rectangular section after vertical bending also increase with the increase of the vertical bending angle

(2) Extend the limited data by machine learning, and find the range of horizontal and vertical bending angles corresponding to the distortion rate less than $2 \%$, greater than $2 \%$, less than $2.5 \%$, greater than $2.5 \%$, less than $3 \%$, and greater than $3 \%$ in the plane. Make a quality control curve that is instructive for production.

\section{Data Availability}

The data used to support the findings of this study are available from the corresponding author upon request.

\section{Conflicts of Interest}

The authors declare that they have no conflicts of interest.

\section{Acknowledgments}

This work was financially supported by the National Science Foundation of China (51675225); Project of Jilin Provincial Scientific and Technological Department (20180201074GX, 20190201110JC, and 20190302037GX); Project of Jilin Provincial Development and Reform Commission (2019C046-2); and Project of Education Department of Jilin Province (JJKH20180130KJ).

\section{References}

[1] H.-Y. Li and X.-C. Lu, "Springback and tensile strength of 2A97 aluminum alloy during age forming," Transactions of Nonferrous Metals Society of China, vol. 25, no. 4, pp. 1043-1049, 2015.

[2] Y. Wang, L. H. Lang, E. Sherkatghanad, K. B. Nielsen, X. X. Li, and Z. Y. Sun, "Rigid-flexible coupling forming process for aluminum alloy automobile body panels," The International Journal of Advanced Manufacturing Technology, vol. 95, no. 9-12, pp. 3905-3918, 2018.

[3] X. F. Lin, Y. Li, Z. Y. Cai et al., "Effect of flexible 3D multipoint stretch bending dies on the shape accuracy and the optimal design," Advances in Materials Science and Engineering, vol. 2018, Article ID 1095398, 9 pages, 2018.

[4] A. H. Clausen, O. S. Hopperstad, and M. Langseth, "Stretch bending of aluminium extrusions for car bumpers," Journal of Materials Processing Technology, vol. 102, no. 1-3, pp. 241-248, 2000.

[5] S. P. Vaze and E. Corona, "Degradation and collapse of square tubes under cyclic bending," Thin-Walled Structures, vol. 31, no. 4, pp. 325-341, 1998.

[6] E. Corona, "A simple analysis for bend-stretch forming of aluminum extrusions," International Journal of Mechanical Sciences, vol. 46, no. 3, pp. 433-448, 2004.

[7] P. P. Dai, Z. D. Chang, M. Li et al., "Reduction of geometric deviation by multi-pass incremental forming combined with tool path compensation for non-axisymmetric aluminum alloy component with stepped feature," The International Journal of Advanced Manufacturing Technology, vol. 102, no. 1-4, pp. 809-817, 2019.

[8] H. H. Li, Z. L. Hu, L. Hua et al., "Optimization of hot formingquenching integrated process parameters for complex aluminum alloy automotive components," Rare Metal Materials and Engineering, vol. 48, no. 4, pp. 1029-1035, 2019.

[9] Y. Q. Xu, C. Y. Tong, L. H. Zhan et al., "A low-density pulsecurrent-assisted age forming process for high-strength aluminum alloy components," The International Journal of Advanced Manufacturing Technology, vol. 97, no. 9-12, pp. 3371-3384, 2018.

[10] F. Teng, J. C. Liang, W. X. Zhang et al., "Springback prediction of rectangular profiles during three-dimension stretch bending forming," Huanan Ligong Daxue Xuebao/Journal of South China University of Technology (Natural Science), vol. 43, no. 2, pp. 107-113, 2015.

[11] J. C. Liang, S. Gao, F. Teng et al., "Flexible 3D stretch-bending technology for aluminum profile," The International Journal of Advanced Manufacturing Technology, vol. 71, no. 9-12, pp. 1939-1947, 2014.

[12] J. Yu, Y. Li, F. Teng et al., "Research on the cross section forming quality of three-dimensional multipoint stretch forming parts," Advances in Materials Science and Engineering, vol. 2018, Article ID 4265617, 11 pages, 2018.

[13] Y. C. Yen, P. Sartkulvanich, and T. Altan, "Finite element modeling of roller burnishing process," CIRP Annals, vol. 54, no. 1, pp. 237-240, 2005.

[14] N. Pillai and R. Karthikeyan, "Prediction of ttt curves of cold working tool steels using support vector machine model," IOP Conference Series: Materials Science and Engineering, vol. 346, no. 1, p. 012067, 2018.

[15] Y. Yan, H.-B. Wang, and M. Wan, "Forming path optimization for press bending of aluminum alloy aircraft integral panel," Journal of Shanghai Jiaotong University (Science), vol. 17, no. 5, pp. 635-642, 2012. 
[16] P. Lopez-Crespo, F. V. D. Camas, and J. R. Yates, "A study of the evolution of crack tip plasticity along a crack front," Theoretical and Applied Fracture Mechanics, vol. 98, pp. 59-66, 2018.

[17] A. Elghawail, K. Essa, M. Abosaf et al., "Prediction of springback in multi-point forming," Cogent Engineering, vol. 4, no. 1, Article ID 1400507, 2017.

[18] M. Abebe, J.-S. Yoon, and B.-S. Kang, "Radial basis functional model of multi-point dieless forming process for springback reduction and compensation," Metals, vol. 7, no. 12, p. 528, 2017.

[19] C. Walter and C. Mitterer, "3D versus 2D finite element simulation of the effect of surface roughness on nanoindentation of hard coatings," Surface \& Coatings Technology, vol. 203, no. 20-21, pp. 3286-3290, 2009. 